\title{
Drug repurposing of nitazoxanide: can it be an effective therapy for COVID-19?
}

\author{
Dina B. Mahmoud ${ }^{1 *}$, Zayyanu Shitu² and Ahmed Mostafa ${ }^{3}$
}

\begin{abstract}
Background: The current outbreak of pandemic coronavirus disease 2019 (COVID-19) aggravates serious need for effective therapeutics. Over recent years, drug repurposing has been accomplished as an important opportunity in drug development as it shortens the time consumed for development, besides sparing the cost and the efforts exerted in the research and development process.

Main body of the abstract: The FDA-approved antiparasitic drug, nitazoxanide (NTZ), has been found to have antiviral activity against different viral infections such as coronaviruses, influenza, hepatitis C virus (HCV), hepatitis B virus (HBV), and other viruses signifying its potential as a broad spectrum antiviral drug. Moreover, it has been recently reported that NTZ exhibited in vitro inhibition of SARS-CoV-2 at a small micromolar concentration. Additionally, NTZ suppresses the production of cytokines emphasizing its potential to manage COVID-19-induced cytokine storm. Furthermore, the reported efficacy of NTZ to bronchodilate the extremely contracted airways can be beneficial in alleviating COVID-19-associated symptoms.

Short conclusion: All these findings, along with the high safety record of the drug, have gained our interest to urge conductance of clinical trials to assess the potential benefits of using it in COVID-19 patients. Thus, in this summarized article, we review the antiviral activities of NTZ and highlight its promising therapeutic actions that make the drug worth clinical trials.
\end{abstract}

Keywords: Broad spectrum antiviral, Bronchodilation, COVID-19, Cytokines, Repurposed nitazoxanide

\section{Background}

The outbreak of recent coronavirus disease 2019 (COVID-19) was firstly identified in Wuhan, China [1], by the end of the year 2019. The main cause for this disease was a novel beta-coronavirus that was recognized as severe acute respiratory syndrome coronavirus-2 (SARS-CoV-2) by the International Committee on Taxonomy of Viruses [2]. Coronaviruses belong to Coronaviridae family within the order Nidovirales. They are enveloped and positive-sense single-stranded RNA viruses. Several coronaviruses infect humans and other mammalian hosts. Coronaviruses are classified into four distinct genera (alpha, beta, delta, and gamma), and

\footnotetext{
*Correspondence: dina_bahaa2007@yahoo.com

'Pharmaceutics Department, National Organization for Drug Control and Research, Giza, Egypt

Full list of author information is available at the end of the article
}

among them, few alpha- and beta-coronaviruses are recognized to infect humans [3]. Coronaviruses are usually zoonotic; however, efficient human-to-human transmission was observed with SARS-CoV-2 rather than SARS$\mathrm{CoV}$ and Middle East respiratory syndrome coronavirus (MERS-CoV) [4]. By June 30, 2020, the World Health Organization (WHO) recorded more than 10 million cases of COVID-19 with nearly half a million deaths worldwide [5], demonstrating that COVID-19 is a critical public health threating disease. Currently, there is neither clinically approved nor currently available antiviral drug for coronavirus treatment. Though remdesivir advanced into human clinical trials as an antiviral agent to treat COVID-19, it is still critically and urgently needed to explore other effective drugs as potential therapy for COVID-19 [6]. Over recent years, drug repurposing has been accomplished as an important

\section{Springer Open}

(c) The Author(s). 2020 Open Access This article is licensed under a Creative Commons Attribution 4.0 International License, which permits use, sharing, adaptation, distribution and reproduction in any medium or format, as long as you give appropriate credit to the original author(s) and the source, provide a link to the Creative Commons licence, and indicate if changes were made. The images or other third party material in this article are included in the article's Creative Commons licence, unless indicated otherwise in a credit line to the material. If material is not included in the article's Creative Commons licence and your intended use is not permitted by statutory regulation or exceeds the permitted use, you will need to obtain permission directly from the copyright holder. To view a copy of this licence, visit http://creativecommons.org/licenses/by/4.0/. 
opportunity in drug development and as a smart strategy involves recognizing new indications for the currently approved or investigated compounds that are out of the scope of their usual medical indications. This strategy is of great interest as it shortens the time consumed for development and safety assessment, besides sparing the cost and the efforts exerted in the research and development process. Moreover, it offers the advantage of decreasing the possibility of drug failure especially from the safety considerations as most of the drugs are repurposed after proving their safety in preclinical or clinical trials [7]. Nitazoxanide (NTZ) was approved in the USA as an antiparasitic therapy for diarrhea and enteritis triggered by Cryptosporidium spp. and Giardia lamblia in 2002 [8]. It targets host pathways by the disruption of mitochondrial respiration [9]. Regarding the safety of NTZ, it was reported that above 75 million patients (including children) administered the drug in postmarketing experience for the treatment of parasitic intestinal infections with no observed critical safety issues correlated to the drug. Besides the antiparasitic action of $\mathrm{NTZ}$, in vitro assessment of the drug revealed an inhibitory action against a wide range of anaerobic grampositive and gram-negative bacteria along with replicating and non-replicating strains of Mycobacterium tuberculosis [10]. Moreover, the activity of NTZ as a treatment for Clostridium difficile disease has been confirmed by animal studies as well as clinical trials [9]. Serendipitous suspicion of the antiviral effect of NTZ was raised while treating cryptosporidial diarrhea in patients suffering co-infection of acquired immune deficiency syndrome (AIDS), with hepatitis B virus (HBV) or hepatitis $C$ virus $(\mathrm{HCV})$ [11]. Since then, extensive investigation of the antiviral therapeutic potential of NTZ and its active metabolite tizoxanide (TIZ) has been conducted. Our aim in this article is to enumerate the exceptional antiviral effects of NTZ and highlight its therapeutic potential to combat the novel COVID-19 (Fig. 1).

\section{Main text}

\section{Nitazoxanide and viral infections}

Nitazoxanide (NTZ) showed a promising activity against a broad spectrum of viruses as summarized in Table 1.

\section{Nitazoxanide and coronaviruses}

Coronaviruses are a number of enveloped, non-segmented positive-sense RNA viruses characterized by a genome size which is very large as it ranges from about 27 to 34 $\mathrm{kb}$. The respiratory infections caused by human strains, namely $\mathrm{HCoV}-229 \mathrm{E}, \mathrm{HCoV}-\mathrm{OC} 43, \mathrm{HCoV}-\mathrm{NL} 63$, and HCoV-HKU1, are typically mild and self-limited, for instance common cold. On the other hand, epidemic and pandemic serious diseases are caused when humans are infected with three highly pathogenic beta-coronaviruses namely SARS-CoV, MERS-CoV, and the latest SARSCoV-2 [6]. Currently, there is an urgent demand for new drug discovery to manage the infections caused by coronaviruses due to the lack of effective treatment options.

In vitro studies revealed that tizoxanide (TIZ) could inhibit the in vitro canine coronavirus S-378 replication

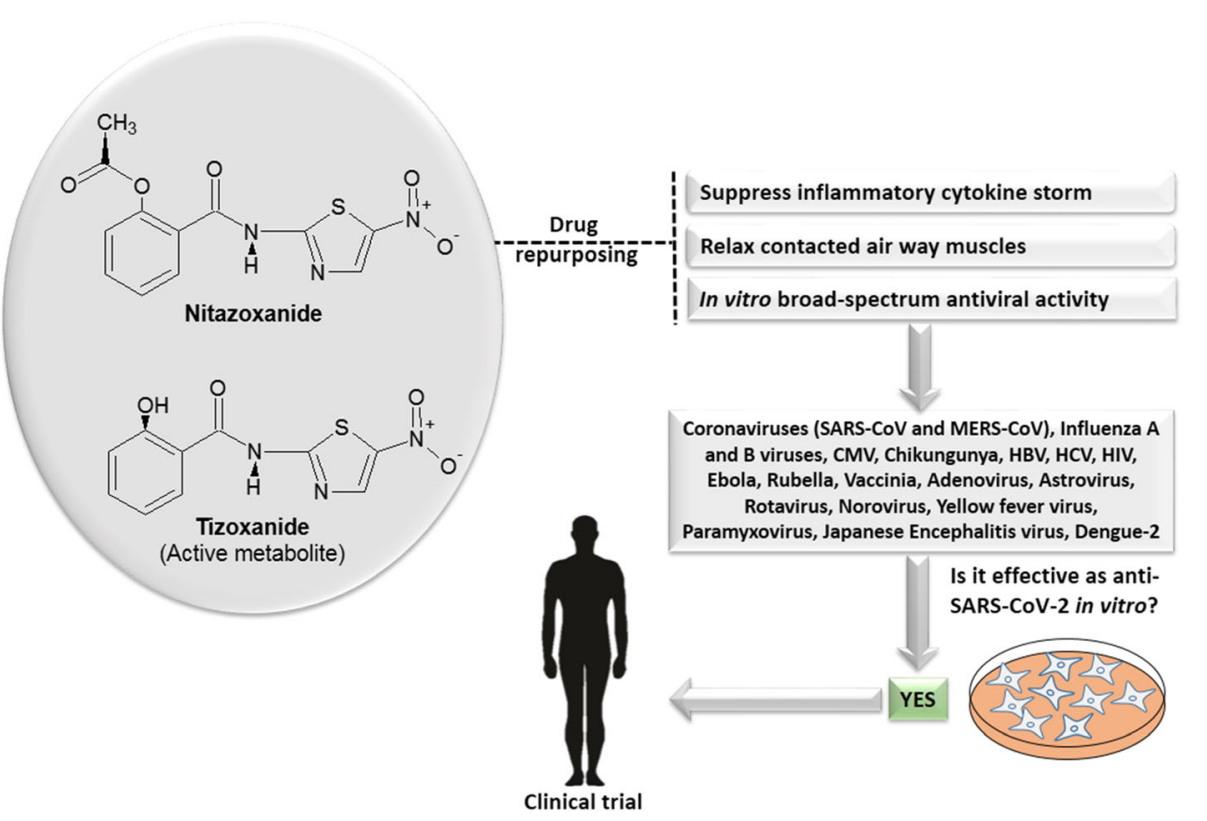

Fig. 1 Drug repurposing of nitazoxanide (NTZ) and its active metabolite tizoxanide (TIZ). NTZ represents a promising medication for clinical trial against COVID-19 due to its ability to control excessive inflammatory immune responses, its bronchodilator effect, and in vitro anti-SARS-CoV-2 activity 
Table 1 The inhibitory effect of NTZ and tizoxanide (TIZ) as broad spectrum antivirals

\begin{tabular}{|c|c|c|c|}
\hline Virus & Dose & Compound & Ref \\
\hline Canine coronavirus S-378 & $\mid \mathrm{C}_{50}, 1 \mu \mathrm{g} / \mathrm{ml}$ & $\mathrm{TIZ}$ & [9] \\
\hline Bovine coronavirus ( $(\mathrm{9})$ & $\mid C_{50}, 0.3 \mu \mathrm{g} / \mathrm{ml}$ & NTZ & [12] \\
\hline Murine coronavirus & $\mid \mathrm{C}_{50}, 0.3 \mu \mathrm{g} / \mathrm{ml}$ & NTZ & [12] \\
\hline Mouse hepatitis virus (A59) & $\mid C_{50}, 0.3 \mu \mathrm{g} / \mathrm{ml}$ & NTZ & [12] \\
\hline Human enteric coronavirus (4408) & $\mid C_{50}, 0.3 \mu \mathrm{g} / \mathrm{ml}$ & NTZ & {$[12]$} \\
\hline MERS-COV & $\mid \mathrm{C}_{50}, 0.92 \mu \mathrm{g} / \mathrm{ml}$ & NTZ & [12] \\
\hline MERS-COV & $\mathrm{IC}_{50}, 0.83 \mu \mathrm{g} / \mathrm{ml}$ & $\mathrm{TIZ}$ & [12] \\
\hline SARS-CoV-2 & $\mathrm{IC}_{50}, 2.12 \mu \mathrm{M}$ & NTZ & {$[1]$} \\
\hline Influenza A strains & $\mid \mathrm{C}_{50}, 0.2-1.5 \mu \mathrm{g} / \mathrm{ml}$ & $\mathrm{TIZ}$ & {$[9]$} \\
\hline Influenza B/Parma/3/04 & $\mid C_{50}, 0.2-1.5 \mu \mathrm{g} / \mathrm{ml}$ & $\mathrm{TIZ}$ & {$[9]$} \\
\hline Rotavirus: the human Wa-G1P (8) & $\mid \mathrm{C}_{50}, 1 \mu \mathrm{g} / \mathrm{ml}$ & $\mathrm{TIZ}$ & {$[9]$} \\
\hline Rotavirus: simian SA11-G3P (2) & $\mid \mathrm{C}_{50}, 0.5 \mu \mathrm{g} / \mathrm{ml}$ & $\mathrm{TIZ}$ & {$[9]$} \\
\hline Norovirus G1 replicon assay system & $\mid C_{50}, 0.5 \mu \mathrm{g} / \mathrm{ml}$ & $\mathrm{TIZ}$ & [13] \\
\hline Human astrovirus & $\mathrm{IC}_{50}, 1.47 \mu \mathrm{M}$ & NTZ & [14] \\
\hline Adenovirus enteritis & 500 mg twice daily & NTZ & [15] \\
\hline Paramyxovirus & $\mid \mathrm{C}_{50}, 10 \mu \mathrm{g} / \mathrm{ml}$ & NTZ & [16] \\
\hline Ebola virus & $\mathrm{IC}_{100}, 20-40 \mu \mathrm{M}$ & NTZ & {$[17]$} \\
\hline HCV genotype 1a & $\mid C_{50}, 0.09 \mu \mathrm{g} / \mathrm{ml}$ & $\mathrm{TIZ}$ & [18] \\
\hline HCV genotype $1 b$ & $\mid C_{50}, 0.06 \mu \mathrm{g} / \mathrm{ml}$ & $\mathrm{TIZ}$ & [18] \\
\hline HBV in clinical trials & $500 \mathrm{mg}$ daily & NTZ & [11] \\
\hline Chikungunya virus & $\mathrm{IC}_{50}, 2.96 \mu \mathrm{M}$ & NTZ & [19] \\
\hline Rubella virus & $\mid \mathrm{C}_{50}, 0.35 \mu \mathrm{g} / \mathrm{ml}$ & NTZ & [20] \\
\hline Vaccinia virus & $\mathrm{IC}_{50}, 2 \mu \mathrm{M}$ & NTZ & {$[21]$} \\
\hline HIV & $\mid C_{50}, 0.5 \mu \mathrm{g} / \mathrm{ml}$ & NTZ & {$[22]$} \\
\hline HIV & $\mid C_{50}, 0.5 \mu \mathrm{g} / \mathrm{ml}$ & $\mathrm{TIZ}$ & [22] \\
\hline Human cytomegalovirus & $\mathrm{IC}_{50}, 3.2 \mu \mathrm{M}$ & NTZ & [23] \\
\hline Dengue-2 virus & $\mid C_{50}, 0.1 \mu \mathrm{g} / \mathrm{ml}$ & $\mathrm{TIZ}$ & [24] \\
\hline Yellow fever virus & $\mid C_{50}, 0.06 \mu \mathrm{g} / \mathrm{ml}$ & $\mathrm{TIZ}$ & [24] \\
\hline Japanese encephalitis & $\mid \mathrm{C}_{50}, 0.12 \mu \mathrm{g} / \mathrm{ml}$ & NTZ & [25] \\
\hline
\end{tabular}

in the infected A72 cells (the reported half maximum inhibitory concentration, $\mathrm{IC}_{50}$, is $1 \mu \mathrm{g} / \mathrm{ml}$ [9]). Cao et al. reported that NTZ could effectively inhibit bovine coronavirus (L9), murine coronavirus, mouse hepatitis virus (A59), and human enteric coronavirus (4408) cultured in mouse astrocytoma (DBT) and fibroblast (17Cl-1) cell lines in an $\mathrm{IC}_{50}$ of about $0.3 \mu \mathrm{g} / \mathrm{ml}$; this effect involved inhibition of the expression of the viral $\mathrm{N}$ protein [12]. It is notable that both NTZ and its active metabolite (TIZ) generally depict comparable in vitro inhibition action on viruses; they inhibit MERS-CoV grown in LLC-MK2 cell lines (the reported $\mathrm{IC}_{50}=0.92$ and $0.83 \mu \mathrm{g} / \mathrm{ml}$, respectively).

In 2020, after the breakdown of COVID-19, Wang et al. have reported that NTZ could inhibit SARS-CoV-2 in Vero E6 cells (ATCC-1586) after infection with SARS-CoV-2/ Wuhan/WIV04/20192 at a low micromolar concentration (a half maximum inhibition concentration of $2.12 \mu \mathrm{M}$ ) [1].
Recently, Kelleni has suggested using NTZ with azithromycin as a protocol for early cases of COVID-19 [26]. Additionally, Pepperrell et al. reviewed the reported clinical research studies about NTZ to determine the safety of the drug and they calculated the minimum cost of drug production for the expected potential use in the treatment of COVID-19 [27]. Currently, there are 14 clinical trials for using NTZ either alone or in combination with other drugs (ivermectin or hydroxychloroquine) to treat COVID-19 patients; among them, 7 studies started recruiting patients as shown in Table 2. The other clinical trials are not recruiting patients yet. The countries that started clinical trials for NTZ are Egypt, the USA, Brazil, and Mexico [28].

\section{Nitazoxanide and influenza viruses}

NTZ readily undergoes hydrolysis and converts to TIZ in aqueous buffers as a cell culture medium [28, 29]. 
Table 2 Current clinical trials to assess NTZ for treatment of COVID-19

\begin{tabular}{lll}
\hline COVID-19-related clinical trials & Country & \multicolumn{1}{c}{ Status } \\
\hline NTZ with ivermectin vs ivermectin with chloroquine & Egypt & Recruiting \\
NTZ for moderate case hospitalized patients & Brazil & Recruiting \\
NTZ for post-exposure prophylaxis in healthcare workers vs placebo vs dietary supplement & USA Recruiting \\
NTZ 500 mg oral tablet & Mexico Recruiting \\
NTZ vs hydroxychloroquine & Mexico Recruiting \\
NTZ vs favipiravir vs chloroquine & Egypt \\
NTZ vs placebo & Egypt \\
\hline
\end{tabular}

Several in vitro studies revealed that TIZ caused inhibition of the replication of sixteen various strains of influenza A viruses (IAV) [A/Puerto Rico/8/34 (H1N1, A/ H1N1-PR8), A/Wisconsin/33 (H1N1), A/Parma/24/09 (H1N1, oseltamivir-resistant), A/Goose/Italy/29624603 (H1N1), A/California/04/p2009 (H1N1), A/Ohio/88/ 2012 (H3N2v), A/Ohio/83/2012 (H3N2v), A/Washington/01/2007 (H3N2), A/Texas/12/2007 (H3N2), A/Firenze/7/03 (H3N2), A/Parma/6/07 (H3N2, amantadineresistant), A/Canine/Colorado-1/224986/06 (H3N8), A/ Canine/Colorado-3/3/06 (H3N8), A/Canine/Colorado-4/ 2025974/07 (H3N8), A/Chicken/Italy/9097/97 (H5N9, $\mathrm{A} / \mathrm{H} 5 \mathrm{~N} 9$ ), and A/Turkey/Italy/RA5563/99 (H7N1)] and one influenza B virus (IBV) [Influenza B/Parma/3/04]. The half maximal inhibitory concentration of TIZ against influenza viruses ranged from 0.2 to $1.5 \mu \mathrm{g} / \mathrm{ml}$ [9]. It was also reported that IAV is not likely to develop resistance to TIZ since thiazolides do not have a direct action against viral RNA or protein [30], and it is reported that the development of viral resistance to the antiviral drugs that target host cell is less expected when compared to virus-specific inhibitors [31]. Moreover, a synergistic antiviral effect was observed upon combining NTZ with oseltamivir or zanamivir against influenza $\mathrm{A} / \mathrm{H} 1 \mathrm{~N} 1-\mathrm{PR} 8$ and the avian A/H5N9 [32].

Tilmanis et al. have reported the potent antiviral effect of TIZ against 210 seasonal influenza viruses as well as viruses that exhibit resistance to neuraminidase inhibitors including oseltamivir, zanamivir, peramivir, and laninamivir [33].

In a human clinical trial involving 257 patients, NTZ could effectively reduce the duration of symptoms of influenza in patients that received oral doses of $600 \mathrm{mg}$ twice daily comparing to the placebo. Additionally, there was a significant decrease in the viral titers in this group of patients when compared to patients that received placebo $(p=0.0006)$. Interestingly, no observable antiviral resistance against NTZ was reported among treated influenza viruses and no adverse events were reported on humoral immune response in the drug-receiving patients [34].

\section{Nitazoxanide and rotavirus}

Viral gastroenteritis that affect children are mostly selflimited infections, and the use of antimicrobial drugs may be not required; however, the use of antimicrobials may be reasonable as diarrheal illness is responsible for more than one million child mortalities on an annual basis in the developing countries [35]. In the developing countries, gastroenteritis disease in pediatric population is mostly caused by rotavirus. Furthermore, it may lead to 500,000 deaths annually in children under the age of 5 years [36]. TIZ was reported to hinder the replication of two strains of rotavirus which are the human WaG1P (8) and simian SA11-G3P (2) at an $\mathrm{IC}_{50}$ of 1 and $0.5 \mu \mathrm{g} / \mathrm{ml}$, respectively [9].

Few clinical trials have revealed the potential benefits of using NTZ against rotavirus causing gastroenteritis. The benefits include reduction in the duration of rotavirus disease in hospitalized pediatric population as compared to placebo, thus signifying that NTZ is a vital treatment option for diarrhea caused by rotavirus [37, 38].

\section{Nitazoxanide and norovirus}

Norovirus is progressively recognized as a major cause of viral gastroenteritis in immunocompromised patients [39]. In 2011, the assessed number of childhood deaths worldwide as a result of norovirus infections is 71,000 [40]. The half maximal inhibitory concentration of TIZ was $0.5 \mu \mathrm{g} / \mathrm{ml}$, in a norovirus G1 replicon assay system utilizing HG-23 cells. Additionally, NTZ was reported to treat norovirus gastroenteritis in a 43-year-old case who was diagnosed with leukemia and subjected to chemotherapy in addition to transplantation of hematopoietic stem cell; the patient experienced an improvement after $24 \mathrm{~h}$ post-treatment [13].

Results of a randomized, 2-phase, double-blind clinical study which was conducted enrolling 200 subjects (including 50 adults and 150 children from 2 months to 11 years old) with viral gastroenteritis induced by the infection with norovirus or rotavirus signified the ability of NTZ for the significant reduction in the duration of disease symptoms when compared with the placebo $(p=$ 0.0295) [41]. Morris and Morris have reported an 
improvement of diarrhea, nausea, and abdominal pain after 2 days of NTZ therapy in a clinical study enrolling 14 patients diagnosed with viral gastroenteritis because of norovirus [42].

Dang et al. have reported a synergistic inhibitory effect of human norovirus replication and complete depletion of the replicons from the host cells after administration of combination therapy of ribavirin and TIZ. Briefly, their results revealed that TIZ inhibits viral replication by stimulation of cellular antiviral response particularly through expression of interferon regulatory factor 1 . Treatment with NTZ alone or in combination with ribavirin represents a promising strategy for combating norovirus-induced gastroenteritis principally in immunosuppressed patients [14].

\section{Nitazoxanide and astrovirus}

Human astrovirus is known to cause 2 to $9 \%$ of acute non-bacterial diarrhea pediatric cases globally. Human astrovirus infections can be fatal particularly in immunocompromised patients as the infection may be associated with necrotizing enterocolitis and severe diarrhea, in addition to other fatal diseases such as respiratory diseases [43], encephalitis, and meningitis [44]. In spite of the high prevalence of astrovirus and the risk of the associated severe diseases, there is currently no vaccine or drug therapy that is available for combating this virus. Hargest et al. have recently reported the first evidence that NTZ can cause in vitro inhibition of the replication of several astrovirus strains as well as in vivo reduction in the viral shed and diarrhea in symptomatic astrovirusinfected turkey poultry model [43]. Their results revealed that NTZ was superior to ribavirin, foscarnet, and acyclovir as they failed in the inhibition of human astrovirus replication even at elevated concentrations $(250 \mu \mathrm{M})$. On the other hand, NTZ could effectively inhibit viral replication in a manner proportional to concentration with an $\mathrm{IC}_{50}$ of $1.47 \mu \mathrm{M}$.

\section{Nitazoxanide and adenovirus}

Human adenoviruses are non-enveloped, doublestranded DNA viruses with icosahedral capsids. Infection with human adenovirus usually leads to severe lifethreatening disease particularly in immunocompromised subjects. At the moment, there is a lack of available specific antiviral drugs against adenovirus infections [6]. Garrigos et al. reported the clinical efficacy of NTZ against adenovirus-related enteritis in a 61-year-old immunocompromised hospitalized patient; the authors detected a speedy recovery of diarrhea and viremia along with a negative PCR result 2 weeks post-initiation of NTZ therapy of $500 \mathrm{mg}$ two times daily dosing regimen. Interestingly, the patient recovered from diarrhea after $48 \mathrm{~h}$ of treatment. It is notable that the limited toxicity and viral resistance of NTZ, as well as the few drug interactions, make it a promising treatment option for such infections [15].

\section{Nitazoxanide and paramyxovirus}

Paramyxoviruses are a group of airborne viruses which are responsible for some respiratory diseases. They include agents of measles, mumps, respiratory syncytial virus, Newcastle disease in poultry, and parainfluenza in human. These viruses are characterized by singlestranded RNA genome and polymerase. They have an envelope of a diameter between 150 and $300 \mathrm{~nm}$. The viruses had been reported in some species of snakes which is transmitted to human [45]. They are highly contagious viruses which induce infection associated with respiratory signs in human, and they are transmitted by respiratory secretions [46].

Piacentini et al. identified in their study the antiparamyxovirus effect of NTZ; they found that NTZ halts the F-trafficking to the plasma by acting on Sendai virus and RSV F-protein aggregate of the viral cell. They further found NTZ acting as an ERp57 non-competitive blocker; the NTZ binding site is said to be located at the ERp57-b/b' non-catalytic domain border [16].

\section{Nitazoxanide and Ebola virus}

Ebola virus is an enveloped negative single-stranded RNA virus. Ebola virus is transmitted to human through wild animals, and it can further spread between humans via transmission from subject to subject. Ebola virus infection is identified as Ebola hemorrhagic fever; it exhibited high mortality rates (25 to $90 \%$ in the previous outbreaks) [6]. Jasenosky and his colleagues have recently reported that NTZ could effectively amplify the host innate immune response and inhibit the replication of Ebola virus. The reported mode of action involves enhancing retinoic-acid-inducible protein I-like receptor as well as mitochondrial antiviral signaling protein. Moreover, NTZ stimulates the expression of interferon regulatory factor 3 and prompts antiviral phosphatase GADD34 transcription thus presenting a promising approach as a therapy for Ebola virus prone disease [17].

\section{Nitazoxanide and hepatitis $C$ virus}

$\mathrm{HCV}$ is an enveloped positive-sense single-stranded RNA virus belonging to the family Flaviviridae. The virus can be transmitted essentially through blood to cause either acute or chronic hepatitis. HCV is encountered as the essential cause of hepatic cancer [6]. TIZ activity against $\mathrm{HCV}$ was primarily investigated in genotype $1 \mathrm{a}$ in the HCV replicon cell culture system grown in AVA5 cells, and genotype $1 \mathrm{~b}$ in the HCV replicon replicated in Huh7.5 cell lines. The $\mathrm{TIZ} \mathrm{IC}_{50}$ for genotype $1 \mathrm{a}$ was $0.09 \mu \mathrm{g} / \mathrm{ml}$, while for genotype $1 \mathrm{~b}$, it was $0.06 \mu \mathrm{g} / \mathrm{ml}$. 
Synergism was also reported upon combining TIZ with interferon $\alpha$ or with $2^{\prime} \mathrm{C}$ methylcytidine [18]. It is noteworthy to mention that $\mathrm{HCV}$ did not show decreased sensitivity to TIZ. Moreover, the sequencing of the viral genome did not experience mutations to develop resistance. Thus, a host-targeted mechanism of action was suggested [47].

Clinical trials were conducted to assess the efficacy of NTZ against HCV with promising outcomes as patients accomplished a sustained virological response without traceable viral RNA in serum after NTZ therapy [11, 48]. Even though the improved outcomes were achieved upon the administration of NTZ combined with peginterferon (PegIFN) as a dual therapy for chronic hepatitis $\mathrm{C}$, development was ceased as a result of discovery of novel direct acting antiviral compounds. Assessment of combinations of NTZ with antiviral agents acting directly for combating chronic $\mathrm{HCV}$ in patients co-infected with HIV may be an interesting research area for future advance.

\section{Nitazoxanide and hepatitis $B$ virus}

HBV is a source of significant progressive liver disease; an estimated number of two billion people are living with HBV in the world, out of which approximately 360 million people are infected chronically [49]. Korba et al. showed how NTZ and its metabolite, TIZ, inhibit HBV DNA and its core antigen. The antigens are of two types, the HBeAg and HBsAg, and they were inhibited in prepared cell cultures. Both molecules were found to be more effective than other antiviral drugs such as lamivudine (LMV) and adefovir dipivoxil (ADV), as they exerted activity against six HBV mutants that were resistant to LMV and ADV [18]. In a recent study, Sekiba and others investigated the inhibitory effect of NTZ against not only the DNA but also the RNA of the HBV virus. They have shown that NTZ targets the protein $\mathrm{HBx}-$ damage specific DNA-binding protein 1 (DDB1) interaction thereby inhibiting the expression of HBV cccDNA and RNA transcription [50]. A recent in vitro study showed that NTZ acts by leading HBsAg loss by restraining serum HBV DNA. NTZ shows an original mechanism of antivirals with the inhibition of oxidative phosphorylation in the mitochondria [51]. Furthermore, clinical trial using $500 \mathrm{mg}$ dose of NTZ given daily for 12 consecutive months to 12 adults patients with hepatitis B showed its effect on HBV. The findings showed that 4 patients of the 12 exhibited HBeAg-positive result and 8 patients exhibited negative HBeAg result. These occurred in an average of 3 months. It clearly shows the therapeutic potential of NTZ on HBV patients [11].

\section{Nitazoxanide and chikungunya virus}

Chikungunya virus is a positive-sense single-stranded RNA virus. Chikungunya virus causes chikungunya disease that is identified by fever, conjunctivitis, arthritis, and severe arthralgia. The infection is transmitted by the female mosquitoes infected with the virus. In 2005, the outbreak of the disease occurred in France, and then, the infection spread to many other countries with hundreds of deaths and greater than one million infected cases [52]. Chikungunya virus is identified as a risk group-3 pathogen [53]. This group of pathogens can enter the cells via receptor-dependent endocytosis. During the entry, conformational changes occur in the viral envelope glycoproteins E1 and E2 [54] which lead to the formation of trimers with subsequent fusion between virus and endosome membranes [55] and release of the viral genome into cytosol. At present, there is no effective approved antiviral drug for treatment of chikungunya infection [6]. A recent study has shown that NTZ could limit both the entry and the release of the virus as well as cell-to-cell transmission. Furthermore, the drug exhibited broad antiviral activity against two clinical chikungunya virus isolates in addition to two types of alphaviruses namely Sindbis virus and Semliki forest virus [19].

\section{Nitazoxanide and rubella virus}

Rubella virus is characterized as a single-stranded positive RNA genome. It is small and enveloped [56]. The disease that is induced by rubella virus is contagious, characterized by rashes, and it is preventable by vaccines. It causes persistent fetus infection during pregnancy, leading to birth defects. The NTZ exerts its significant effect on rubella virus by inhibiting its replication in a primary culture of human umbilical vein endothelial cells in a concentration-dependent manner with an $\mathrm{IC}_{50}$ of $0.35 \mu \mathrm{g} / \mathrm{ml}[20]$.

\section{Nitazoxanide and vaccinia virus}

Vaccinia virus is utilized as a vector for the delivery of the other antigens [57]. Nevertheless, the virus is able to induce a severe disease in immunosuppressed subjects and also in patients suffering from eczema. Hickson et al. investigated the potential antiviral effect of NTZ against vaccinia virus. Their study demonstrated that NTZ could inhibit vaccinia virus replication with an $\mathrm{IC}_{50}$ of $2 \mu \mathrm{M}$ [21].

\section{Nitazoxanide and human immunodeficiency virus}

HIV infection is devastating to humans since 30 years as a minimum. Since then, HIV infected 60 million subjects and caused more than 25 million deaths. Highly active antiretroviral therapy is available and effective treatment strategy for acquired immune deficiency patients; this 
strategy typically includes a combination of three drugs from two or more classes. For instance, two drugs belonging to the class of nucleoside reverse transcriptase inhibitors are combined with a third drug from these classes: integrase inhibitors, non-nucleoside reverse transcriptase inhibitors, or protease inhibitors. As a result of the high cost of the currently available drugs and the potential serious side effects, development of new antiviral drugs is needed [58]. Tan et al. found that both NTZ and the metabolite TIZ could effectively inhibit the replication of $\mathrm{HIV}\left(\mathrm{IC}_{50}\right.$ was about $\left.0.5 \mu \mathrm{g} / \mathrm{ml}\right)$. Additionally, NTZ exhibited synergistic antiviral effects when combined with some HIV drugs including inhibitors of integrase (raltegravir), nucleoside, and non-nucleoside reverse transcription namely azidothymidine and efavirenz, respectively [22].

\section{Nitazoxanide and human cytomegalovirus}

More than $60 \%$ of human population is susceptible to human cytomegalovirus infections globally. The highly risk group of population includes acquired immune deficiency patients and immunocompromised subjects since the significances of cytomegalovirus infections may cause severe and life-threatening complications [59]. Mercorelli et al. have recently reported that NTZ specifically targets viral transcription factor IE2 functions thus blocking the replication of the virus with an $\mathrm{IC}_{50}$ of 3.2 $\mu \mathrm{M}$. These findings signified a promising antiviral effect of NTZ that is needed to treat congenital infections and the development of strains that can resist the current anti-DNA polymerase compounds [23].

\section{Nitazoxanide and other viruses}

TIZ could effectively inhibit the replication of both dengue- 2 and yellow fever in Vero cell lines with half maximal inhibitory concentrations of 0.1 and $0.06 \mu \mathrm{g} / \mathrm{ml}$, respectively [24]. Another study depicted the activity of NTZ in the inhibition of Japanese encephalitis viral replication in BHK-21 cells with an $\mathrm{IC}_{50}$ of $0.12 \mu \mathrm{g} / \mathrm{mL}$; in vivo activity of NTZ was also studied on mice infected with a fatal dose of Japanese encephalitis virus, and the results revealed that the infected mice could survive after they received NTZ orally for a period of 25 days. On the other hand, all untreated mice died on the ninth day of the experiment. The survival of the mice was proportional to the administered doses as the observed survival was $30 \%, 70 \%$, and $90 \%$ for NTZ doses of 50,75 , and $100 \mathrm{mg} / \mathrm{kg} /$ day, respectively [25].

\section{Nitazoxanide and pro-inflammatory mediators}

Besides the antiviral activity of NTZ, the ability of NTZ to inhibit pro-inflammatory cytokine production including TNF $\alpha$, interleukin (IL)-2, IL-4, I-5, IL-6, IL-8, and IL-10 in PBMC (peripheral blood mononuclear cells) was also reported [60]. Other studies support these findings reporting that $100 \mathrm{mg} / \mathrm{kg}$ oral dose of NTZ when given to mice $2 \mathrm{~h}$ prior to $1 \mathrm{ml}$ of $4 \%$ thioglycollate injected intraperitoneally decreased plasma IL-6 levels by $90 \%$ when compared to vehicle [61]. The findings suggest that NTZ can improve the cytokine storm that may be experienced with severe COVID-19 patients [62] through suppression of the overproduction of proinflammatory cytokines.

\section{Nitazoxanide and bronchodilatation}

In a recent study, Miner and his colleagues reported that NTZ is a potent $\mathrm{Ca}^{+2}$-activated $\mathrm{Cl}^{-}$channel (TMEM16A) antagonist that causes blockade in the contraction and depolarization of the airway smooth muscles. They assessed NTZ efficacy in harsh conditions utilizing extremely contracted airways or airways that were subjected to a cytokine cocktail, and the results revealed that the drug could surprisingly bronchodilate airways. Their findings suggest the potential benefit of using NTZ in COVID-19 patients as it may help to alleviate the disease-associated symptoms [63].

\section{Discussion and future perspectives}

NTZ exhibits extraordinary broad spectrum antimicrobial activity [64]. In the USA, NTZ gained FDA approval as an antiparasitic drug for the treatment of cryptosporidiosis and giardiasis infections. Owing to its safety and activity against a wide range of viral infections, it is currently under assessment in many clinical trials for a number of infectious viral diseases $[65,66]$. The standard treatment with $500 \mathrm{mg}$ dose of NTZ adequately achieves TIZ plasma levels greater than $10 \mu \mathrm{M}$ within 1 $\mathrm{h}$ post-dosing, and plasma levels of TIZ are maintained above that concentration until about $5 \mathrm{~h}$ after dosing with a maximum plasma concentration of $\sim 35 \mu \mathrm{M}$ [67]. After $10 \mathrm{~h}$ post-dosing, the plasma levels of TIZ start to drop below the $\mathrm{IC}_{50}$ signifying that the standard dosing regimen of NTZ will be adequate to maintain effective antiviral concentrations throughout the treatment. A published study reported that the administration of a high single dose $(4 \mathrm{~g})$ of NTZ achieved a maximum plasma concentration of approximately $200 \mu \mathrm{M}$ in patients and even this high dose was well tolerated without toxicity [68]. These data suggest the possibility of combating COVID-19 as the reported IC $_{50}$ against SARSCoV-2 is only $2.12 \mu \mathrm{M}$, and that can be easily achieved with the typical dosing of NTZ.

The COVID-19 outbreak is considered as a threat for public health and a global emergency to search for novel effective treatment options to hinder the rapid spreading of the lethal COVID-19 which is urgently necessitated. Drug repurposing campaigns can reduce the cost and time required for developing new molecules. It is 
recently reported that some screened current drugs such as NTZ, chloroquine, and remdesivir were proved to inhibit the fatal SARS-CoV-2 using low concentrations in cultured Vero E6 cell lines with $\mathrm{IC}_{50}$ values of $2.12 \mu \mathrm{M}$, $1.13 \mu \mathrm{M}$, and $0.77 \mu \mathrm{M}$, respectively. It is reported in a Chinese study that oseltamivir, which is a drug that is commonly used for influenza A and B, had no positive effects as a treatment for COVID-19 [69]. However, oseltamivir is currently investigated as an antiviral drug in some clinical trials [70]. Additionally, ivermectin which possesses a potent anthelmintic effect has recently exhibited an in vitro inhibitory effect against SARS-CoV2 within $48 \mathrm{~h}$ with an $\mathrm{IC}_{50}$ of approximately $2 \mu \mathrm{M}$ [71]. There are some limitations of using these repurposed drugs; for example, the use of ivermectin may include some safety issues as the safety data on using the drug in children weighing less than $15 \mathrm{~kg}$ are inadequate [72]. Moreover, the use of ivermectin in pregnancy may be limited as it is categorized as a FDA class $\mathrm{C}$ drug and there is no sufficient data on its safe use during pregnancy [73]. Furthermore, chloroquine may induce toxicities when used for old patients or above dosing limits; several severe side effects can occur during fetus development if chloroquine is used during pregnancy. Additionally, high doses of chloroquine or hydroxychloroquine can exacerbate retinopathy [74]. Although the FDA has just granted an emergency approval for chloroquine and hydroxychloroquine use in COVID-19 [75], this authorization has recently been revoked based on the latest results of the clinical trials which revealed that these drugs exhibited no benefits in decreasing mortality or accelerating recovery and these results are in accordance with the recent data that revealed that these drugs are not likely to cause inhibition of SARS-CoV-2. Since COVID-19 is a pandemic disease, the cost of treatment is of great importance. The treatment options need to be accessible at affordable prices especially to middle- and low-income countries. Also in high-income countries, the burden of COVID-19 necessitates the availability of drugs at minimal costs [76]. Newly developed antiviral drugs such as remdesivir, favipiravir, and lopinavir/ritonavir are available at higher costs, and this should be taken into consideration during screening therapies available for SARS-CoV-2 infections. On the other hand, NTZ is one of the most promising treatment options for COVID-19 based on the post-marketing experience which demonstrated high safety record in both adult and children as aforementioned. Moreover, NTZ is classified as a pregnancy class B drug by the FDA [77]. Taking into consideration all these data, along with the broad spectrum antiviral properties of NTZ and its affordable price, suggests that NTZ can be a cost-effective and safe drug therapy against SARS-CoV-2. Consequently, we envision that repurposing NTZ as an effective antiviral therapy in fast-track clinical trials may combat the fatal COVID-19 and save the lives of a large number of patients.

\section{Conclusion}

In conclusion, the available reported data suggest the potential therapeutic effects of NTZ in the treatment of SAR-CoV-2 with particular emphasis on (i) in vitro inhibitory action of NTZ against SARS-CoV-2 and other coronaviruses with easily attainable concentration, (ii) the inhibitory effect against pro-inflammatory cytokines including the suppression of IL-6 production, (iii) bronchodilatory effect, and (iv) a satisfactory safety record verified by the clinical trials and in extensive postmarketing experience.

\section{Abbreviations}

COVID-19: Coronavirus disease of 2019; SARS-CoV: Severe acute respiratory syndrome coronavirus; MERS-CoV: Middle East respiratory syndrome

coronavirus; AIDS: Acquired immune deficiency syndrome; HBV: Hepatitis B virus; HCV: Hepatitis C virus; HIV: Human immunodeficiency virus;

PBMC: Peripheral blood mononuclear cells; IL: Interleukin; NTZ: Nitazoxanide; TIZ: Tizoxanide; TNF-a: Tumor necrosis factor-a; PCR: Polymerase chain reaction

\section{Acknowledgements}

Not applicable

\section{Authors' contributions}

DB designed the work, reviewed the literature, and drafted the manuscript; ZS reviewed the literature and drafted the manuscript; AM substantively revised the manuscript and approved the submission. The author(s) read and approved the final manuscript.

\section{Funding}

This work was funded in part by the Egyptian Academy of Scientific Research \& Technology (ASRT) within the "Apply your idea" program "project ID: 7303, To M.A." The funders had no role in the study design, data collection and analysis, decision to publish, or preparation of the manuscript.

Availability of data and materials

Not applicable

Ethics approval and consent to participate

Not applicable

Consent for publication

Not applicable

\section{Competing interests}

The authors declare that they have no competing interests.

\section{Author details}

'Pharmaceutics Department, National Organization for Drug Control and Research, Giza, Egypt. ${ }^{2}$ Hospital Services, Management Board, Ministry of Health, Zamfara State, Gusau, Nigeria. ${ }^{3}$ Centre of Scientific Excellence for Influenza Viruses, National Research Centre, Cairo, Egypt.

Received: 13 May 2020 Accepted: 22 July 2020

Published online: 28 July 2020

\section{References}

1. Wang M, Cao R, Zhang L, Yang X, Liu J, Xu M et al (2020) Remdesivir and chloroquine effectively inhibit the recently emerged novel coronavirus (2019-nCoV) in vitro. Cell Research. 30:269-271 
2. Huang C, Wang Y, Li X, Ren L, Zhao J, Hu Y et al (2020) Clinical features of patients infected with 2019 novel coronavirus in Wuhan. China. Lancet. 395: 497-506

3. Fehr AR, Perlman S (2015) Coronaviruses: an overview of their replication and pathogenesis. Methods Mol Biol. 1282:1-23

4. Chan JF, Yuan S, Kok KH, To KK, Chu H, Yang J et al (2020) A familial cluster of pneumonia associated with the 2019 novel coronavirus indicating person-to-person transmission: a study of a family cluster. Lancet. 395:514523

5. WHO. WHO Coronavirus Disease (COVID-19) Dashboard. 2020

6. Xu J, Shi P-Y, Li H, Zhou J (2020) Broad spectrum antiviral agent niclosamide and its therapeutic potential. ACS Infectious Diseases. 6:909-915

7. Pushpakom S, lorio F, Eyers PA, Escott KJ, Hopper S, Wells A et al (2019) Drug repurposing: progress, challenges and recommendations. Nature reviews Drug discovery. 18:41-58

8. Amadi B, Mwiya M, Musuku J, Watuka A, Sianongo S, Ayoub A et al (2002) Effect of nitazoxanide on morbidity and mortality in Zambian children with cryptosporidiosis: a randomised controlled trial. Lancet. 360:1375-1380

9. Rossignol JF (2014) Nitazoxanide: a first-in-class broad-spectrum antiviral agent. Antiviral research. 110:94-103

10. de Carvalho LP, Lin G, Jiang X, Nathan C (2009) Nitazoxanide kills replicating and nonreplicating Mycobacterium tuberculosis and evades resistance. Journal of medicinal chemistry. 52:5789-5792

11. Rossignol JF, Keeffe EB (2008) Thiazolides: a new class of drugs for the treatment of chronic hepatitis B and C. Future microbiology. 3:539-545

12. Cao J, Forrest JC, Zhang X (2015) A screen of the NIH Clinical Collection small molecule library identifies potential anti-coronavirus drugs. Antiviral research. 114:1-10

13. Siddiq DM, Koo HL, Adachi JA, Viola GM (2011) Norovirus gastroenteritis successfully treated with nitazoxanide. J Infect. 63:394-397

14. Dang W, Xu L, Ma B, Chen S, Yin Y, Chang K-O et al (2018) Nitazoxanide inhibits human norovirus replication and synergizes with ribavirin by activation of cellular antiviral response. Antimicrobial agents and chemotherapy. 62:e00707-e00718

15. Esquer Garrigos Z, Barth D, Hamdi AM, Abu Saleh OM, Sohail MR (2018) Nitazoxanide Is a Therapeutic Option for Adenovirus-Related Enteritis in Immunocompromised Adults. Antimicrobial agents and chemotherapy. 62

16. Piacentini S, La Frazia S, Riccio A, Pedersen JZ, Topai A, Nicolotti O et al (2018) Nitazoxanide inhibits paramyxovirus replication by targeting the Fusion protein folding: role of glycoprotein-specific thiol oxidoreductase ERp57. Sci Rep. 8:10425

17. Jasenosky LD, Cadena C, Mire CE, Borisevich V, Haridas V, Ranjbar S et al (2019) The FDA-Approved Oral Drug Nitazoxanide Amplifies Host Antiviral Responses and Inhibits Ebola Virus. iScience 19:1279-1290

18. Korba BE, Montero AB, Farrar K, Gaye K, Mukerjee S, Ayers MS et al (2008) Nitazoxanide, tizoxanide and other thiazolides are potent inhibitors of hepatitis B virus and hepatitis C virus replication. Antiviral research. 77:56-63

19. Wang YM, Lu JW, Lin CC, Chin YF, Wu TY, Lin LI et al (2016) Antiviral activities of niclosamide and nitazoxanide against chikungunya virus entry and transmission. Antiviral research. 135:81-90

20. Perelygina L, Hautala T, Seppänen M, Adebayo A, Sullivan KE, Icenogle J (2017) Inhibition of rubella virus replication by the broad-spectrum drug nitazoxanide in cell culture and in a patient with a primary immune deficiency. Antiviral research. 147:58-66

21. Hickson SE, Margineantu D, Hockenbery DM, Simon JA, Geballe AP (2018) Inhibition of vaccinia virus replication by nitazoxanide. Virology. 518:398405

22. Tan X, Hu L, Luquette LJ 3rd, Gao G, Liu Y, Qu H et al (2012) Systematic identification of synergistic drug pairs targeting HIV. Nature biotechnology. 30:1125-1130

23. Mercorelli B, Luganini A, Nannetti G, Tabarrini O, Palù G, Gribaudo G et al (2016) Drug Repurposing approach identifies inhibitors of the prototypic viral transcription factor IE2 that block human cytomegalovirus replication. Cell chemical biology. 23:340-351

24. Botta L, Rivara M, Zuliani V, Radi M (2018) Drug repurposing approaches to fight Dengue virus infection and related diseases. Frontiers in bioscience (Landmark edition) 23:997-1019

25. Shi Z, Wei J, Deng X, Li S, Qiu Y, Shao D et al (2014) Nitazoxanide inhibits the replication of Japanese encephalitis virus in cultured cells and in a mouse model. Virology journal. 11:10
26. Kelleni MT (2020) Nitazoxanide/azithromycin combination for COVID-19: a suggested new protocol for early management. Pharmacological Research. 157:104874

27. Pepperrell T, Pilkington V, Owen A, Wang J, Hill AM (2020) Review of safety and minimum pricing of nitazoxanide for potential treatment of COVID-19. J Virus Erad. 6:52-60

28. Broekhuysen J, Stockis A, Lins RL, De Graeve J, Rossignol JF (2000) Nitazoxanide: pharmacokinetics and metabolism in man. International journal of clinical pharmacology and therapeutics. 38:387-394

29. Duszynski DW, Kvičerová J, Seville RS. Chapter 18 - Treatment and drug therapies of coccidiosis in carnivora. In: Duszynski DW, Kvičerová J, Seville $\mathrm{RS}$, editors. The Biology and Identification of the Coccidia (Apicomplexa) of Carnivores of the World: Academic Press; 2018. p. 445-63.

30. Stachulski AV, Santoro MG, Piacentini S, Belardo G, Frazia S, Pidathala C et al (2018) Second-generation nitazoxanide derivatives: thiazolides are effective inhibitors of the influenza A virus. Future medicinal chemistry. 10:851-862

31. Loregian A, Mercorelli B, Nannetti G, Compagnin C, Palu G (2014) Antiviral strategies against influenza virus: towards new therapeutic approaches. Cellular and molecular life sciences: CMLS. 71:3659-3683

32. Belardo G, Cenciarelli O, La Frazia S, Rossignol JF, Santoro MG (2015) Synergistic effect of nitazoxanide with neuraminidase inhibitors against influenza A viruses in vitro. Antimicrobial agents and chemotherapy. 59: 1061-1069

33. Tilmanis D, van Baalen C, Oh DY, Rossignol JF, Hurt AC (2017) The susceptibility of circulating human influenza viruses to tizoxanide, the active metabolite of nitazoxanide. Antiviral research. 147:142-148

34. Haffizulla J, Hartman A, Hoppers M, Resnick H, Samudrala S, Ginocchio C et al (2014) Effect of nitazoxanide in adults and adolescents with acute uncomplicated influenza: a double-blind, randomised, placebo-controlled, phase 2b/3 trial. The Lancet Infectious diseases. 14:609-618

35. Arun Babu T, Venkatesh C (2010) Nitazoxanide use in rota viral diarrhea. Cure or controversy? The Indian Journal of Pediatrics 77:1450

36. Tan EM, Cawcutt KA, Zomok CD, Go RS, Sia IG (2017) Activity of nitazoxanide against viral gastroenteritis: a systematic review. International Journal of Travel Medicine and Global Health. 5:107-112

37. Rossignol JF, Abu-Zekry M, Hussein A, Santoro MG (2006) Effect of nitazoxanide for treatment of severe rotavirus diarrhoea: randomised double-blind placebo-controlled trial. Lancet. 368:124-129

38. Teran CG, Teran-Escalera CN, Villarroel P (2009) Nitazoxanide vs. probiotics for the treatment of acute rotavirus diarrhea in children: a randomized, single-blind, controlled trial in Bolivian children. International journal of infectious diseases : IJID : official publication of the International Society for Infectious Diseases 13:518-523

39. Lopman BA, Steele D, Kirkwood CD, Parashar UD (2016) The vast and varied global burden of norovirus: prospects for prevention and control. PLoS medicine. 13:e1001999

40. van Beek J, van der Eijk AA, Fraaij PL, Caliskan K, Cransberg K, Dalinghaus M et al (2017) Chronic norovirus infection among solid organ recipients in a tertiary care hospital, the Netherlands, 2006-2014. Clinical microbiology and infection: the official publication of the European Society of Clinical Microbiology and Infectious Diseases 23:265.e9-265e13

41. Rossignol JF, El-Gohary YM (2006) Nitazoxanide in the treatment of viral gastroenteritis: a randomized double-blind placebo-controlled clinical trial. Alimentary pharmacology \& therapeutics. 24:1423-1430

42. Morris J, Morris C (2015) Nitazoxanide is effective therapy for norovirus gastroenteritis after chemotherapy and hematopoietic stem cell transplantation (HSCT). Biology of Blood and Marrow Transplantation. 21: S255-S2S6

43. Hargest V, Sharp B, Livingston B, Cortez V, Schultz-Cherry S (2020) Astrovirus replication is inhibited by nitazoxanide in vitro and in vivo. J Virol. 94

44. Vu DL, Cordey S, Brito F, Kaiser L (2016) Novel human astroviruses: novel human diseases? Journal of clinical virology : the official publication of the Pan American Society for Clinical Virology. 82:56-63

45. Ariel E (2011) Viruses in reptiles. Vet Res 42:100

46. Blahak S, Jenckel M, Höper D, Beer M, Hoffmann B, Schlottau K (2020) Investigations into the presence of nidoviruses in pythons. Virology journal $17: 6$

47. Yon C, Viswanathan P, Rossignol JF, Korba B (2011) Mutations in HCV nonstructural genes do not contribute to resistance to nitazoxanide in repliconcontaining cells. Antiviral research. 91:233-240 
48. Rossignol JF, Elfert A, El-Gohary Y, Keeffe EB (2009) Improved virologic response in chronic hepatitis $C$ genotype 4 treated with nitazoxanide peginterferon, and ribavirin. Gastroenterology. 136:856-862

49. Chen SL, Morgan TR (2006) The natural history of hepatitis C virus (HCV) infection. Int J Med Sci. 3:47-52

50. Sekiba K, Otsuka M, Ohno M, Yamagami M, Kishikawa T, Suzuki T et al (2019) Inhibition of HBV transcription from cccDNA with nitazoxanide by targeting the HBx-DDB1 interaction. Cellular and molecular gastroenterology and hepatology. 7:297-312

51. Rossignol J-F, Bréchot C (2019) A pilot clinical trial of nitazoxanide in the treatment of chronic hepatitis B. Hepatology Communications. 3:744-747

52. Weaver SC, Forrester NL (2015) Chikungunya: evolutionary history and recent epidemic spread. Antiviral research. 120:32-39

53. Staples JE, Breiman RF, Powers AM (2009) Chikungunya fever: an epidemiological review of a re-emerging infectious disease. Clinical infectious diseases : an official publication of the Infectious Diseases Society of America. 49:942-948

54. Voss JE, Vaney M-C, Duquerroy S, Vonrhein C, Girard-Blanc C, Crublet E et al (2010) Glycoprotein organization of Chikungunya virus particles revealed by X-ray crystallography. Nature. 468:709-712

55. van Duijl-Richter MK, Hoornweg TE, Rodenhuis-Zybert IA, Smit JM (2015) Early Events in chikungunya virus infection-from virus cell binding to membrane fusion. Viruses. 7:3647-3674

56. Chaari A, Bahloul M, Berrajah L, Ben Kahla S, Gharbi N, Karray H et al (2014) Childhood rubella encephalitis: diagnosis, management, and outcome. Journal of child neurology. 29:49-53

57. Chan WM, McFadden G (2014) Oncolytic poxviruses. Annu Rev Virol. 1:119141

58. Hawkins $T$ (2010) Understanding and managing the adverse effects of antiretroviral therapy. Antiviral research. 85:201-209

59. Nogalski MT, Collins-McMillen D, Yurochko AD (2014) Overview of human cytomegalovirus pathogenesis. In: Yurochko AD, Miller WE (eds) Human cytomegaloviruses: methods and protocols. Humana Press, Totowa, NJ, pp 15-28

60. Clerici M, Trabattoni D, Pacei M, Biasin M, Rossignol J-F (2011) The antiinfective nitazoxanide shows strong immumodulating effects (155.21). The. Journal of Immunology. 186:155.21

61. Hong SK, Kim HJ, Song CS, Choi IS, Lee JB, Park SY (2012) Nitazoxanide suppresses IL-6 production in LPS-stimulated mouse macrophages and TGinjected mice. International Immunopharmacology. 13:23-27

62. Mehta P, McAuley DF, Brown M, Sanchez E, Tattersall RS, Manson JJ (2020) COVID-19: consider cytokine storm syndromes and immunosuppression. Lancet. 395:1033-1034

63. Miner K, Labitzke K, Liu B, Wang P, Henckels K, Gaida K et al (2019) Drug repurposing: the anthelmintics niclosamide and nitazoxanide are potent TMEM16A antagonists that fully bronchodilate airways. Frontiers in Pharmacology. 10

64. Shakya A, Bhat HR, Ghosh SK (2018) Update on nitazoxanide: a multifunctional chemotherapeutic agent. Current drug discovery technologies. 15:201-213

65. Koszalka P, Tilmanis D, Hurt AC (2017) Influenza antivirals currently in latephase clinical trial. Influenza and other respiratory viruses. 11:240-246

66. Galan-Herrera JF, Poo JL, Rosales-Sanchez O, Fuentes-Fuentes E, Cariño L, Burke-Fraga $V$ et al (2009) Bioavailability of two oral formulations of a single dose of levofloxacin 500 mg: an open-label, randomized, two-period crossover comparison in healthy Mexican volunteers. Clinical therapeutics. 31:1796-1803

67. Balderas-Acata Jl, Ríos-RogríguezBueno EP, Pérez-Becerril F, EspinosaMartínez C, Fraga VB, Parra MG-dl. Bioavailability of two oral-suspension formulations of a single dose of nitazoxanide $500 \mathrm{mg}$ : an open-label, randomized-sequence, two-period crossover, comparison in healthy fasted Mexican adult volunteers. 2011.

68. Stockis A, Allemon AM, De Bruyn S, Gengler C (2002) Nitazoxanide pharmacokinetics and tolerability in man using single ascending oral doses. International journal of clinical pharmacology and therapeutics. 40:213-220

69. Wang D, Hu B, Hu C, Zhu F, Liu X, Zhang J et al (2020) Clinical characteristics of 138 hospitalized patients with 2019 novel coronavirusinfected pneumonia in Wuhan. China. JAMA. 323:1061-1069

70. Wu R, Wang L, Kuo H-CD, Shannar A, Peter R, Chou PJ et al (2020) An update on current therapeutic drugs treating COVID-19. Curr Pharmacol Rep.:1-15
71. Caly L, Druce JD, Catton MG, Jans DA, Wagstaff KM (2020) The FDAapproved drug ivermectin inhibits the replication of SARS-CoV-2 in vitro. Antiviral research. 178:104787

72. Levy M, Martin L, Bursztejn AC, Chiaverini C, Miquel J, Mahé E et al (2020) Ivermectin safety in infants and children under $15 \mathrm{~kg}$ treated for scabies: a multicentric observational study. The British journal of dermatology. 182: 1003-1006

73. Patel VM, Lambert WC, Schwartz RA (2016) Safety of topical medications for scabies and lice in pregnancy. Indian J Dermatol. 61:583-587

74. Zhou D, Dai S-M, Tong Q (2020) COVID-19: a recommendation to examine the effect of hydroxychloroquine in preventing infection and progression. Journal of Antimicrobial Chemotherapy. 75:1667-1670

75. FDA. Coronavirus (COVID-19) update: FDA revokes emergency use authorization for chloroquine and hydroxychloroquine. 2020.

76. Hill A, Wang J, Levi J, Heath K, Fortunak J (2020) Minimum costs to manufacture new treatments for COVID-19. J Virus Erad. 6:61-69

77. Domjahn BT, Hlavsa MC, Anderson B, Schulkin J, Leon J, Jones JL (2014) A survey of U.S. obstetrician-gynecologists' clinical and epidemiological knowledge of cryptosporidiosis in pregnancy. Zoonoses and public health 61:356-363

\section{Publisher's Note}

Springer Nature remains neutral with regard to jurisdictional claims in published maps and institutional affiliations.

\section{Submit your manuscript to a SpringerOpen ${ }^{\circ}$ journal and benefit from:}

- Convenient online submission

- Rigorous peer review

- Open access: articles freely available online

High visibility within the field

- Retaining the copyright to your article

Submit your next manuscript at $\boldsymbol{\nabla}$ springeropen.com 